\title{
CONFERENCIA: VERDAD Y MEMORIA NUEVOS DESAFÍOS ÉTICOS EN LAS ORGANIZACIONES GLOBALES
}

Jean-Philippe Bouilloud

\section{Resumen}

Este artículo contiene la transcripción de la conferencia magistral de Jean-Philippe Bouilloud en el Coloquio Repensando la Relación Europa-América Latina en un Mundo en Disrupción, organizado por el Centre d'Etudes et de Recherche Amérique Latine Europe (CERALE) y la Universidad de los Andes (UNIANDES) en 2018. El coloquio tuvo como ejes la innovación, el emprendimiento y el desarrollo sostenible, y se realizó en la sede UNIANDES de Cartagena de Indias (Colombia) entre el 30 de mayo y el 1 de junio de 2018.

Palabras clave: ética, historia, verdad, memoria.

\section{Abstract}

Conference: Truth and memory. New ethical challenges in global organizations

This article contains the transcript of the master conference by Jean-Philippe Bouilloud at the Colloquium Rethinking the Europe-Latin America relationship in a world in disruption, organized by the Center d'Etudes et de Recherche Amérique Latine Europe (CERALE) and the University of Los Andes (UNIANDES) in 2018. The colloquium focused on innovation, entrepreneurship and sustainable development and took place at the UNIANDES campus in Cartagena de Indias (Colombia) between May 30 and June 1, 2018.

Keywords: ethics, history, truth, memory.

Jean-Philippe Bouilloud: Profesor de Organización y Epistemología y Sociología de las Ciencias en la Escuela Superior de Comercio de París (ESCP) Business School. Graduado de la Escuela de Estudios Superiores de Comercio (HEC) de París. Tiene un doctorado en Sociología y una habilitación posdoctoral para la dirección de Investigaciones. También es profesor de la Universidad de París VII y de varias universidades de otros países.

ORCID iD: 0000-0003-3843-6769

Email: bouilloud@escp.eu 


\section{Introducción}

En materia de verdad e información nos encontramos ante un mundo nuevo. Las revelaciones recurrentes de los lanzadores de alertas (whistleblower) sobre empresas u organizaciones, los nuevos métodos de espionaje a gran escala en los países desarrollados, la presión ejercida por las redes sociales, así como las nuevas formas de influencia basadas en algoritmos y en el big data (a modo de ejemplo, pensemos en Cambridge Analytica y la cuestión del Brexit) hacen que estemos ante nuevos desafíos en materia de ética de la verdad.

Además, como veremos con algunas empresas, lo económico y lo político actúan a menudo en connivencia. ¿Cuál es la línea ética divisoria entre lo que es aceptable hacer en un contexto restrictivo y lo que hay que prohibir? ¿Cuál es la responsabilidad de una empresa — persona moralrespecto a los comportamientos de sus antiguos directivos - personas físicas-? ¿Qué hacer con un molesto pasado que no se reconoce? Se trata, al mismo tiempo, de una cuestión moral y de una cuestión sobre lo que Ricoeur llama "justa memoria".

Al preparar esta conferencia, me vinieron a la mente varias ideas relacionadas con numerosas obras: en primer lugar, El coraje de la verdad, del último año académico de Michel Foucault en el Collège de France; en segundo lugar, La memoria, la historia, el olvido, de Paul Ricoeur; y, por último, Truth and truthfullness, de Bernard Williams. Me gustaría invitarlos hoy a una especie de diálogo entre estas obras, desde la perspectiva de nuestra actualidad política y económica, por medio de algunos ejemplos ilustrativos.

\section{Frente al pasado: la cuestión de la justa memoria}

Hay una ética de la verdad, según Williams, y un coraje de la verdad, según Foucault, pero ¿hay una ética, o un coraje, de la memoria y del olvido? Eso es lo que vamos a analizar a partir de Ricoeur.

\section{Renault y Hugo Boss: la cuestión de la memoria}

La compañía Renault, propiedad de Louis Renault, trabajó mucho para los alemanes en la Segunda Guerra Mundial, al punto tal que los aliados bombardearon las fábricas de Renault para reducir la producción. Louis Renault era, además, partidario de un acercamiento entre Francia y Alemania, y próximo 
a los movimientos franceses de extrema derecha (Cagoule, Croix de Feu). Tras la guerra se le recriminaron su enérgica implicación a favor de los alemanes y sus simpatías con el régimen de Pétain: ahí donde él veía una orden que debía obedecer, otros veían simpatía por los nazis. La compañía Renault fue nacionalizada en 1945 y luego nuevamente privatizada, pasando a cotizar en bolsa en los años noventa.

En comparación con otros fabricantes franceses, como Peugeot, que no fueron muy cooperativos con el ocupante e intentaron no colaborar demasiado, incluso protegiendo resistentes, Renault fue víctima de un conjunto de factores que aceleraron su nacionalización: la personalidad autoritaria del dirigente, su clara simpatía hacia la extrema derecha y su gran implicación con los alemanes en el esfuerzo bélico.

El segundo ejemplo es Hugo Boss. La firma Hugo Boss, creada en 1924, fue el principal proveedor de ropa del ejército alemán y del partido nazi. Al parecer, su fundador estaba afiliado al partido nazi desde 1931. Fue condenado tras la guerra por haber sido "nazi por oportunismo", y tras su muerte, en 1948, la compañía pasó a ser dirigida por su yerno.

En su página web no es fácil encontrar este breve recordatorio histórico:

"In the past HUGO BOSS AG has often been confronted by vague statements regarding its history. Hugo Ferdinand Boss established his workshop in 1924, as a consequence of which his company operated during the Third Reich and the Second World War. During this period the factory employed 140 forced laborers (the majority of them women) and 40 French prisoners of war. When the Group became aware of this fact, it made a contribution to the international fund set up to compensate former forced laborers.

Out of respect to everyone involved, the Group has published this new study with the aim of adding clarity and objectivity to the discussion. It also wishes to express its profound regret to those who suffered harm or hardship at the factory run by Hugo Ferdinand Boss under National Socialist rule." (web de Hugo Boss).

El análisis de este texto es interesante. Al mencionar que la empresa se fundó en 1924, se indica que vivió el período de la Alemania nazi como una simple constatación histórica, omitiendo el hecho de que su fundador estaba afiliado al partido nazi desde 1931 y que su principal cliente era el régimen nazi. Por otro lado, en la web, la historia de la compañía actual solo empieza en 1946, en un deseo de ruptura — u olvido — respecto a los abusos del pasado. Este trabajo de memoria se hizo, sobre todo, bajo la presión de algunos periodistas norteamericanos, que obligó a Hugo Boss a financiar un estudio histórico ${ }^{1}$ y a participar en la creación de un fondo de indemnización para los trabajadores

Köster, 2011. 
forzados. La tentación de separar la "persona moral" de la empresa (nacida en 1946) de la "persona física" de los actores no basta: es un recurso que no logra proteger la reputación de la empresa. Vemos bien aquí cómo se opera una "reconfiguración" de la memoria en el relato que se hace.

\section{Imagen 1. Publicidad de Hugo Boss}

\section{SA., $\mathcal{H}$ S., 69.-2Inijormen \\ Arbeits=, Sport= u. Regentsleidurg \\ ous eigenet 'terstellung in bekann' guten Qualitaten und billigen Preisen}

\section{ooss}

Mech. Berufskleiderfabrik, Metzingen

Zugelassene Lieferfirma für SA. und SS.

Uniformen der Reichszeugmeisterei

München unter $\mathrm{Nr}, 53$

Fuente: Hugo Boss, 1934: "SA, SS, HJ (HitlerJugend) Uniformen".

\section{Pensar la memoria con Ricoeur}

La reflexión sobre el tiempo en la obra de Paul Ricoeur empieza en los años ochenta (Ricoeur, 1983) y culmina con su última gran obra, La memoria, la historia, el olvido (2000), en la que el autor aborda las cuestiones de las posibilidades de la historia y el lugar de la memoria en la sociedad. Su planteo utiliza conceptos que pueden ser útiles para reflexionar sobre los desafíos de la memoria en las organizaciones.

En primer lugar, para pensar la historia hay que pasar por "aquello que hace memoria": no puede haber historia sin hechos, datos o relato que cuenten lo que ocurrió en el pasado. Para Ricoeur, la historia es la sabia heredera de la memoria (Ricoeur, 2000), y la historia siempre es un relato que se encarga de dar sentido a un pasado, por medio de una configuración y unas formas narrativas, reconociendo lo que es sabido por todos (trabajadores forzados en 
el caso de Boss), pero minimizando los elementos negativos (por ejemplo, la inscripción de Hugo F. Boss en el partido nazi).

Cualquier reflexión histórica empieza, por tanto, con una reflexión sobre la memoria, y Ricoeur establece aquí la distinción entre mneme (memoria) y anamnesis (reminiscencia), entre el recuerdo que surge y el esfuerzo por recordar. En el ámbito de las organizaciones, la historia es vista como algo que debe ser controlado: la revelación de algo vergonzoso en el pasado puede llevar a la organización a un cuestionamiento doloroso (Anteby y Molnár, 2012) o a que vuelva a aparecer pese a los esfuerzos de los directivos. La organización prefiere así a anamnesis y desconfía de mneme, a quien no puede controlar: el gran reto de la "rhetorical history" (Suddaby et al., 2010) es lograr sacar la máxima ventaja competitiva de esta historia que viene de la mneme.

No obstante, para la reflexión sobre la dirección de una organización, lo más interesante de Ricoeur quizás sea su visión de la ética de la memoria y la historia. Ricoeur subraya que, de hecho, la mirada histórica puede convertirse en mirada ética, pues historiadores y jueces tienen una presunción de imparcialidad y el historiador, como el juez, ocupa una posición de tercero y aspira o pretende ser imparcial. Así, cuando Boss encarga a un historiador que examine el pasado de la empresa se está exponiendo ipso facto a su juicio, mostrando el papel central de ese tercero, que aparece también en los procesos de reconciliación en los países que conocieron dictaduras, apartheids o guerras civiles, a través de instituciones como la Comisión Nacional sobre la Desaparición de Personas (CONADEP) en Argentina, la Comisión Verdad y Reconciliación en África del Sur, etcétera.

Para Ricoeur, la historia implica una política de la justa memoria o, en otros términos, una ética de la memoria. Distingue tres tipos de problemas éticos: la memoria imposibilitada o lesionada (por ejemplo, tras un trauma), la memoria "abusivamente ordenada" u obligada y la memoria manipulada (por ejemplo, por la ideología). Apunta que, en la mayoría de los casos, la memoria manipulada es más un abuso de olvido que un abuso de memoria (2000, p. 97). Retomando la noción de mise en intrigue (puesta en intriga), presente en muchas de sus obras, Ricoeur muestra que es la narratividad del relato la que revela las estrategias de olvido o rememoración.

Con la memoria obligada, el autor evoca la cuestión del deber de memoria, que trae necesariamente a colación la noción de deuda, en la medida en que los coetáneos se sitúan en una posición de deudores respecto a quienes les han precedido: aquí se plantean las cuestiones de arrepentimiento y reconciliación, intentadas por numerosos países que han vivido una transición democrática tras períodos de dictadura o "dictablanda".

Ricoeur indica, al final de su obra, hasta qué punto el perdón es difícil, aunque este perdón le parece indispensable para reconciliar al cuerpo político con su pasado. Sin embargo, la posición de Ricoeur plantea dos 
cuestiones o problemas. La primera cuestión se refiere al estatus de la justicia: si el perdón se concibe como prácticamente la única posibilidad de una "memoria feliz", de un cuerpo político reconciliado consigo mismo, se olvida la dimensión catártica y reparadora que tiene la función jurídica: el proceso, mediante una reafirmación solemne a cargo de los representantes de la sociedad (jueces) y condenando al culpable, permite a la víctima realizar su duelo. Antes del perdón está la justicia; el perdón solo puede venir legítimamente después.

Más aún, al oponer memoria y olvido, Ricoeur pasa por alto un elemento muy apreciado por las organizaciones: el secreto. Pues si el olvido no se encomienda, el secreto se organiza: y aquí es por donde se les puede hacer daño a las empresas. Para Simmel (1906), las interacciones sociales se basan en diferentes formas de conocimiento imperfecto o disimulado y, sobre todo, en el secreto, que forma nuestras relaciones sociales por nuestra capacidad de decir o callar informaciones, protegiendo así a un individuo o grupo contra la sociedad exterior. El secreto es una forma de mantenerse al margen. El término viene del latín secretus (separado, sin testigos), que deriva de secernere (poner aparte, expulsar, eliminar), lo que nos remite a un aspecto principal del secreto: "está tan ausente en ciertos lugares como presente en otros" (Rouillé, 2004). Una de las funciones del secreto, según lo analiza Simmel, es permitir escapar al control y, por tanto, al poder del otro, aunque también hace posible ocultar acciones heroicas o positivas, en las que el secreto es una garantía del valor. Así, pues, para Simmel, el secreto es éticamente neutro, dominado únicamente por la intención subyacente y el contexto.

Más aún, Simmel constata que los intercambios sociales se apoyan a menudo en un conocimiento imperfecto del otro, en imágenes y percepciones necesariamente incompletas: por lo tanto, el error y las aproximaciones tienen en definitiva tanta importancia social como la verdad, que para Simmel no es el eje de las interacciones. El reclamo de franqueza no queda, por lo tanto, obsoleto, por ser al mismo tiempo — dado que la verdad puede no ser conocida - irrealista socialmente e imposible lógicamente. Sin embargo, en las organizaciones, la estrategia del secreto no puede escudarse en la imprecisión de las relaciones sociales usuales: se trata, por lo contrario, de una estrategia narrativa, de un deseo de poner aparte que permite preservar el poder o la reputación, porque la revelación del secreto comprometería el poder o la reputación (cosas coincidentes, pues la reputación es fuente de poder). La clave de este esfuerzo por olvidar es, en efecto, la conservación del poder que evoca Simmel. La cuestión de la memoria, como la del secreto, se convierte así en la cuestión de aquello que conviene decir y sus consecuencias. 


\section{La tensión ética de la verdad en las organizaciones}

Todos o casi todos conocemos el caso Enron, que fue noticia durante su quiebra en 2001 y que precipitó, a su vez, la de Arthur Andersen y sus auditores. La compañía Enron, que era una de las que mayor cotización tenía en las bolsas norteamericanas, había creado innumerables estructuras offshore para ocultar sus lamentables especulaciones, todo lo cual fue organizado y validado por Andersen.

El igualmente conocido y más reciente caso Volkswagen sacó a la luz que la empresa falseó los programas de funcionamiento de los motores para cumplir con normas restrictivas sin pérdida del rendimiento de los coches. La revelación del caso provocó un escándalo oneroso y la dimisión de muchos de sus directivos.

La cuestión que se plantea en ambos casos es la de saber quién, entre todos los directivos, sabía qué, así como la cuestión de la mentira. La idea preconcebida sobre la verdad es que es una suerte de imperativo categórico, que se impone naturalmente y que debe reinar de forma natural y evidente. Lo que voy a debatir aquí no es la noción de imperativo categórico de la verdad (tampoco haré una apología de la mentira o del secreto), sino más bien la idea de que la verdad pueda reinar de un modo natural y evidente. En efecto, la verdad, en la práctica, y sobre todo en el mundo económico y en el de las organizaciones, se encuentra en una situación paradójica, pues se puede al mismo tiempo exigir y prohibir: ¿qué hacer, entonces?

\section{Una paradoja ${ }^{2}$}

Un dirigente tiene la obligación de decir la verdad sobre su organización, sobre su situación económica y financiera, pues si no lo hace puede ser sancionado por los accionistas y los mercados financieros, arriesgándose incluso a ser encarcelado: es lo que ocurrió cuando quebró Enron. Inversamente, un dirigente que confiesa una mala noticia sabe que repercutirá negativamente en la cotización de las acciones, algo que los accionistas podrán reprocharle si el valor de sus acciones disminuye.

Es lo que yo llamaría una situación de tensión ética, en la que la idea de lo que debe hacerse de manera justa no es evidente a priori, sino algo que se construye según la situación. Esta complejidad cuestiona la idea preconcebida y demasiado simple de que la verdad debe decirse y de que es bueno decir cualquier verdad.

Otro ejemplo de esta tensión ética es el de los lanzadores de alertas (whistleblowers). La literatura sobre este tema indica que el lanzador de alertas es visto positivamente desde afuera y negativamente desde adentro: traiciona a la organización, al mismo tiempo que revela sus fallos. Ello 
plantea, por tanto, otra tensión ética, la de saber a quién hay que ser fiel: ¿se ha de ser fiel a la verdad en sí misma o a la organización? Si consideramos la primera opción, kantiana, el imperativo categórico de Kant ante la verdad es para él una necesidad social: decir siempre la verdad es bueno para la sociedad en general, sin que deba establecerse ninguna excepción.

No obstante, la obligación de decir siempre la verdad también plantea problemas éticos, paradójicos y estudiados desde hace tiempo. Los justos, que ocultaron a los judíos durante la guerra, estaban claramente del lado del secreto o de la mentira y, por evidentes razones morales, tampoco debían contarlo todo. Aquí nos encontramos con la propuesta de Benjamin Constant, mediante la interesante noción de "derecho a la verdad". Volviendo al ejemplo clásico de un posible asesino que busca a alguien escondido en su casa, Constant manifiesta que "allí donde no hay derecho, no hay deberes. Decir la verdad solo es un deber respecto a quienes tienen derecho a saber la verdad. Sin embargo, nadie tiene derecho a saber la verdad que daña a otro" (Constant, citado en Kant, 1986 [1797], p. 436). Kant se opone a esta visión con el pretexto de que mentir perjudica a la humanidad en general (pues la mentira socava el edificio de las leyes y las interacciones entre los individuos), y que entre estos dos males hay que optar por el menos malo, esto es, en definitiva, decir la verdad, independientemente de sus consecuencias directas. En este caso, la obligación de hablar con franqueza tiene graves consecuencias, y en cualquier caso vemos bien que no tenga un carácter tan evidente como podríamos fácilmente atribuirle.

Como hemos dicho, hablar con franqueza es una reivindicación, una exigencia que se extiende a toda la empresa y funciona como una obligación paradójica. Por un lado, se les exige a los directivos que sean transparentes $\mathrm{y}$, al mismo tiempo, se legisla (o se intenta legislar) para proteger el secreto de los negocios, lo que supone la imposibilidad de proteger a los lanzadores de alertas, quienes también se encuentran en tensión entre el deseo de no encubrir comportamientos delictivos y el temor sobre las consecuencias que podría conllevar su revelación.

En la tradición filosófica, estas cuestiones las encontramos en la noción de parresia (franqueza), tal y como fue abordada por Platón, Aristóteles y los cínicos. Vamos a recurrir a los autores clásicos a partir de un estudio exhaustivo realizado por Michel Foucault durante su último año en el Collège de France (Foucault, 2009), que lleva el bonito título de El coraje de la verdad (Bouilloud et al., 2017).

El término griego utilizado es el de parresi $\alpha$, cuya polisemia muestra una maraña primordial de sentido: "libertad de lenguaje, sinceridad al hablar, franqueza", por un lado, aunque también significa, a veces, "audacia, atrevimiento". 
Esta definición plantea tres tipos de cuestiones:

- La figura ontológicamente bífida, positiva y negativa de la parresia: hablar con franqueza no es únicamente positivo, también tiene algo de negativo.

- La dimensión subjetiva y moral implícita de quien ejerce la parresia, que es a la vez sincero sin dejar de estar en los límites de la libertad.

- El contexto social que permite esta libertad o que, por el contrario, la considera excesiva (es el caso de los cínicos, como veremos más adelante) y en cualquier caso como un factor de riesgo (noción retomada por Sócrates). ¿A qué se opone la parresia? En primer lugar, a la mentira, pero también a la adulación (tratado de Plutarco sobre la adulación), al secreto o a lo que no se dice.

Foucault señala que la palabra parresia se utilizó inicialmente para designar el "derecho a hablar", a tomar la palabra en público (Foucault, 2009, p. 33). Era un privilegio ciudadano; si utilizáramos una expresión del francés medieval diríamos tener voix au chapitre, es decir, derecho a hablar en el cabildo. Es aquí donde reside la libertad, en el ejercicio de este derecho cuyos límites aún no han sido determinados. Efectivamente, la facultad de expresarse está socialmente delimitada por el espectro de lo que puede decirse. Lo que indican los filósofos antiguos es que uno de los riesgos políticos de la parresia es su "peligrosidad para la ciudad, pues es la libertad de tomar la palabra que se da a todos y a cualquiera" (Foucault, 2009, p. 35). Foucault cita, a propósito de la "mala parresia" el Libro VIII de La república, en el que la mala ciudad, "abigarrada, dislocada, dispersa entre intereses diferentes, pasiones diferentes", no se reúne en torno a una verdad. Esta libertad de palabra, generalizada, supone un problema, pues pone en entredicho los fundamentos de la sociedad. Más aún, aunque pueda seducir por su forma retórica, la libertad de hablar no dice nada sobre la verdad que contiene lo que se dice. La parresia fomenta los conflictos y los enfrentamientos.

La parresia, como hemos visto, no es unívoca, tiene sus propios límites, con sentidos a la vez positivos y negativos. Decir la verdad, o decir supuestamente la verdad, puede ser un "decirlo todo", que es también decir cualquier cosa, algo ya constatado por Platón en La república (Libro VIII) y retomado por Foucault:

"La parresia, utilizada de modo peyorativo, consiste en decirlo todo, en el sentido de decir cualquier cosa (cualquier cosa que se te pase por la cabeza, cualquier cosa que pueda ser útil para la causa defendida, cualquier cosa que pueda servir a la pasión o el interés de quien habla). Quien utiliza la parresia se convierte así en un charlatán empedernido, que no sabe controlarse o, en cualquier caso, en alguien que no es capaz de ajustar su discurso a un principio de racionalidad y a un principio de verdad." (Foucault, 2009, p. 11). 
Esto nos aclara sobre dos puntos. El primero, que aparece implícitamente, es que la "buena parresia" se basa en la lógica, la verdad y la realidad, y necesita para ello el control de uno mismo y su razón. El segundo es que la buena parresia unifica, permite el diálogo, el intercambio, permite encontrar soluciones colectivas al problema encontrado, sea político, empresarial o de management: no es tanto el hecho de que exista una sola verdad, sino, sobre todo, que la franqueza y la coherencia lógica permitan superar la diversidad centrífuga de los intereses de cada uno.

La parresia, tan ambivalente como el pharmakon, al mismo tiempo remedio y enfermedad, no se deja acotar tan fácilmente como la idea preconcebida de "decirlo todo" o una verdad sin negatividad. Al contrario, la tradición filosófica subraya la dificultad de la frontera: entre el ejercicio de una libertad legítima y su abuso, entre la práctica ética de la verdad y sus incertidumbres, entre la comodidad moral de quien actúa bien y los riesgos a los que se expone.

\section{¿Decir "lo verdadero"?}

¿Pero cómo podemos estar seguros de decir "lo verdadero", de decir "la verdad en sí misma"? ¿Cómo evitar la parte de subjetividad en lo que decimos, en lo que consideramos como verdadero? Además, hay una parte que no se dice en la afirmación de lo verdadero, hay un papel que juega lo indecible/ inexplicable, lo confidencial, el secreto, lo abyecto, lo que se reprime, además de la comunicación indirecta, etcétera, que merecería un análisis más exhaustivo.

¿Se puede acceder a lo verdadero? Un seguidor de Karl Popper diría que no, que nos aproximamos sin estar nunca seguros de alcanzarlo. Un relativista podría decir que es una cuestión que depende del punto de vista, del paradigma. Veamos, para empezar, lo que podemos decir sobre lo verdadero.

La palabra griega es aletheia (alhqei $\alpha$ ), verdad que significa también 'realidad'. El término tiene varios significados, como subraya Foucault (2009, p. 201):

1. Es lo "no oculto"; A-lethes: no oculto, no olvidado (Lhqך, lethe, el olvido), "siempre presente en la mente".

2. Lo que "no recibe ninguna adición ni suplemento, lo que no sufre ninguna mezcla".

3. Lo que es recto, directo, sin rodeos.

4. "Lo que existe y perdura más allá de cualquier cambio".

Lo anterior merece varios comentarios. En primer lugar, lo verdadero como aquello "no olvidado" nos hace pensar en la ética de la memoria de Ricoeur y nos recuerda que lo que escapa al conocimiento escapa también a lo real: en cierto modo, lo desconocido no existe o deja de existir, que es lo que quieren creer las organizaciones que intentan ocultar verdades problemáticas. 
En segundo lugar, la verdad está ligada a las condiciones de producción, a un contexto, depende de su "aparición" (Heidegger hablaba de la "revelación"): la verdad tiene que ser pura, exenta de cualquier desnaturalización humana, accesible, estable. Para nosotros, los modernos, esta verdad está más cerca de la verdad como correspondencia, tal y como fue desarrollada por Tarski, y que la palabra aletheia designe a la vez a la verdad y a la realidad es prueba de ello. No se dan aquí los obstáculos lógicos planteados por Russell en el siglo XIX o por Williams en el XX. La verdad es aquí transparencia, un "no oculto", un "no encriptado", para tomar las palabras de los psicoanalistas Abraham y Torok (1976).

Esta aletheia se aproxima mucho, en definitiva, a aquello que se les pide a los auditores de cuentas y contables, que deben facilitar los datos contables como un retrato "fiel" de la situación de la organización. Además, en caso de observar algo irregular, los auditores de cuentas tienen un "deber de alerta", que puede interpretarse en cierto modo como una exigencia de parresia.

\section{¿Qué coraje de la verdad?}

Si tomamos en cuenta la cuestión de la ética de la memoria y la tensión ética de la verdad, ¿qué significado atribuir al "coraje de la verdad"? Trataremos de mostrar aquí que el coraje de la verdad no solo debe exigirse a las personas, sino también a las instituciones y al Estado. De no ser así, el resultado sería una negación oficial, aunque la historia se mantenga siempre activa, pero escondida "en la cripta" (Abram y Torok), sepultada y reprimida. Es decir, la ausencia de un discurso oficial de la sociedad sobre sí misma impide cualquier posibilidad de duelo por parte de las víctimas o sus descendientes (pues la injusticia, o el sentimiento de injusticia respecto a sus descendientes, se transmite por herencia).

\section{Franqueza: detrás del riesgo y el coraje, la esperanza}

El ejercicio de la palabra siempre está confrontado con el poder. Hablar con franqueza conlleva un riesgo: el de suscitar reacciones negativas de quien oye esa verdad. Así, la verdad genera o puede generar violencia. Foucault cuenta que Platón, al decirle a Dionisio el Viejo algunas cosas, ciertas pero desagradables para el tirano, había aceptado el riesgo de que el tirano lo matara. La práctica de la parresia requiere coraje, que puede entenderse como "el término medio entre el miedo y la audacia" (Ética nicomáquea III, VI, 1). Mientras que el miedo se define como "una espera de la desgracia" (idem), Aristóteles concluye, asimismo, que "el cobarde es de alguna manera contrario a la esperanza" (idem, III, VII, 11). En la esencia del coraje está el riesgo y aquello que "merece la pena" hacer. En la Apología de Sócrates, este se pregunta por qué no se había implicado antes en la vida de la ciudad. Y su respuesta es cla- 
ra: "Si me hubiera entregado a la política, estaría muerto desde hace mucho tiempo" (Foucault, 2009, p. 37, Apología, 31 d-e). La rectitud de un comportamiento ávido de justicia impide abrazar una carrera política.

“AAcaso piensan que podría haber vivido tantos años si me hubiera ocupado de los asuntos de la república y que, como hombre de bien, podría haber despreciado todo lo demás para pensar solo en defender la justicia? Esto es así, atenienses: ni yo ni nadie podría haberlo hecho." (Apología, 32 e).

Por lo tanto, para hablar con franqueza es necesario poder esperar: esperar que las cosas cambien, que la verdad consiga hacer justicia. Cuanto más fuerte sea el poder, menor es la libertad de palabra, pues menos esperanza hay y, por tanto, menos posible es la parresia: las organizaciones autocráticas, al igual que los sistemas totalitarios, son aquellos donde la parresia es casi imposible por ser demasiado arriesgada.

El lanzador de alertas, ya sea Snowden u otro, tiene la esperanza de que su revelación cambie algo. De igual modo, quien lee un informe financiero espera parresia de los comisarios de cuentas y un comportamiento futuro de la empresa en consonancia con lo que está leyendo sobre ella. La grandeza de la parresia reside, por tanto, en su posibilidad emancipadora, en una apertura al futuro. Si el interlocutor es de la misma índole que quien habla, si tiene la misma "grandeza del alma" (la megalopsukia) o si no tiene relaciones directas con el poder, entonces estará dispuesto, podemos suponer, a escuchar la verdad. De no ser así, el riesgo es que, dejándose llevar por su ira o su negativa a escuchar, ponga fin al diálogo o, incluso, elimine al locutor si tiene el poder para ello. Así, la práctica de la parresia es también una prueba de fuego: de quien habla, pues demuestra su coraje, y de quien escucha, pues demuestra su capacidad para aceptar cosas que pueden ser negativas para él.

Lo que es válido para el individuo lo es también para las organizaciones o grupos. La noticia verdadera, si es negativa, tiene siempre mala prensa: Casandra fue asesinada por Clitemnestra tras la muerte de toda su familia; Laocoonte, que advirtió a los troyanos sobre el caballo abandonado en el arenal ("Timeo danaos et dona ferentes..."), murió devorado por dos serpientes de mar; y las ocas del Capitolio... son ocas. El coraje es hacer frente a esa negatividad futura. Este coraje de la verdad, por utilizar la bella expresión de Foucault, es entonces y al mismo tiempo una verdad del coraje frente al riesgo que se corre (Foucault, 2009, p. 145). No olvidemos que uno de los términos en griego para testigo es marturon, el mártir, que muere por haber testificado su verdad.

En las organizaciones, esta "muerte social" es a la que se expone el lanzador de alertas o quien puede decir una verdad que no gusta. Pero la obligación jurídica a la parresia, por ejemplo, para los dirigentes o auditores, crea un riesgo simétrico: el de la condena por no haber sido sincero, lo que le 
ocurrió a Enron o a Arthur Andersen. Porque sin parresia ya no hay confianza. ¿Y qué otra cosa se le pide a un auditor sino ser digno de confianza, ya que en él se delegan los análisis y controles? Esta tensión entre dos riesgos también se da en el asesoramiento, entre la solicitud de parresia que se espera de una opinión exterior y el posible miedo de una organización a la expresión de esta verdad. Toda la retórica del asesor está en practicar la parresia sin generar una excesiva violencia que no pueda controlar. Pues hay una violencia en decir la verdad. Y esta violencia no es necesariamente la de quien no acepta la verdad cuando debería aceptarla: es la de verse obligado a afrontar una realidad que el sujeto reprimía.

\section{Conclusión: el esfuerzo hacia lo verdadero}

El dirigente es responsable de lo que se dice hacia adentro o hacia afuera en lo que respecta a la verdad, ya se trate de la actividad cotidiana o de la historia de su empresa. Por eso, con mis colegas Ghislain Deslandes y Guillaume Mercier nos referimos al líder como chief truth officer, 'maestro de la verdad' (Bouilloud et al., 2017).

El coraje de la verdad no es solo algo momentáneo, de la oportunidad del momento, del kairós: es también una regla de acción, una "misión" (Foucault, 2009, p. 78), una disciplina respecto a sí mismo. De este modo, decir la verdad se define en relación con hacer oír lo verdadero, que le es consustancial: cuando lo verdadero no se escucha, quienes dicen la verdad no son más que unas "casandras", a la manera de espectadores de una catástrofe anunciada, o condenados jurídica o socialmente, como ocurre con los whistleblowers cuando la expresión de la verdad no tiene una acogida favorable. Lo cual significa que, para el dirigente, no basta con decir la verdad, sino que tiene que acompañar el discurso de lo verdadero con la capacidad de conseguir que se manifiesten las consecuencias positivas de la verdad.

La verdad como reivindicación preside el trabajo del filósofo inglés Bernard Williams. El ideal de veracidad que desarrolla Williams, en la línea de Nietzsche, es una honestidad, una sinceridad, una transparencia de sí, una voluntad de no ser engañado y de no engañar. Para Nietzsche es una y la misma cosa: "no quiero engañar ni tampoco engañarme" (Gaya ciencia, 344; en Williams, 2006, p. 28). De ahí que se dirija más bien hacia la veracidad, como esfuerzo o impulso hacia lo verdadero, "sinceridad y exactitud" (Williams, 2006, p. 118). Así, las dificultades de elaboración o búsqueda de la verdad quedan en un segundo plano, detrás de este "esfuerzo de sinceridad", que es finalmente la vara de medida utilizada para evaluar las opiniones de los auditores o las declaraciones de los dirigentes.

En una época de revelaciones de todo tipo y, al mismo tiempo, de dominación de las fake news, cuando el big data persigue todo lo que hacemos, cuando las redes sociales permiten boicotear rápidamente productos 
u organizaciones, el esfuerzo hacia lo verdadero no es solo un imperativo ético, es también una necesidad pragmática: contar con las posibilidades de una disimulación, ocultar lo que antes o después se sabrá y que saldrá con la fuerza de todo lo que se reprime, es asumir un gran riesgo para el dirigente.

Este esfuerzo hacia lo verdadero es señal de una "vida bella", para tomar a las palabras de Foucault. En la preocupación griega de percibir "la existencia como una obra que hay que realizar en toda su posible perfección [...] se combinan el objetivo de una belleza de la existencia y la tarea de rendir cuentas de uno mismo en el juego de la verdad." (Foucault, 2009, p. 151). Existe, pues, una relación entre una ética individual y una "estética de la existencia" (Foucault, 2009, p. 141). Hablar con verdad es en sí lo "más bello en el hombre", nos dice Diógenes Laercio (Foucault, 2009, p. 154). Esta elección es responsabilidad de cada uno, especialmente para cualquier dirigente en la organización. En este imperativo entre ética y estética, el coraje de la verdad hace posible la "verdadera vida", el alethe bios del que habla Foucault.

\section{Referencias bibliográficas}

Abraham, N. y M. Torok (1976). Le verbier de l'homme aux loups. París: Garnier Flammarion.

Anteby, M., y V. Molnár (2012). Collective Memory Meets Organizational Identity: Remembering to Forget in a Firm's Rhetorical History. Academy of Management Journal, 55(3), pp. 515-540.

Aristóteles (1965). Ethique de Nicomaque. París: Garnier Flammarion.

Bouilloud, J. P.; G. Deslandes y G. Mercier (2017). The leader as chief truth officer: the ethical responsibility of "managing the truth" in organizations. Journal of Business Ethics, 1, 10.1007/s10551-017-3678-0.

Foucault, M. (2009). Le courage de la vérité. Le gouvernement de soi et des autres II. Cours au Collège de France 1984. París: EHESS-Gallimard-Le Seuil.

Kant, E. (1986 [1797]). Sur un prétendu droit de mentir par humanité. En Kant, E. CEuvres complètes, Tomo 3. París: Gallimard-La Pléiade.

Roman Köster (2011). Hugo Boss, 1924-1945: die Geschichte einer Kleiderfabrik zwischen Weimarer Republik und "Drittem Reich". Schriftenreihe zur Zeitschrift für Unternehmensgeschichte. Munich: Verlag C. H. Beck.

Ricoeur, P. (1983). Temps et récit. París: Seuil. 
Ricoeur, P. (2000). La mémoire, l'histoire, l'oubli. París: Seuil.

Rouillé, E. (2004). Le secret ou l'Aléthéia grecque. Le Portique. Revue de Philosophie et de Sciences Humaines, 2. Disponible en: <http://leportique. revues.org/465>.

Simmel, G. (1906). The Sociology of Secrecy and of the Secret Societies. American Journal of Sociology, 11, pp. 441-498.

Suddaby, R. y W. M. Foster (2017). History and Organizational Change. Journal of Management, 43(1), pp. 19-38.

Williams, B. (2006). Vérité et véracité. París: Gallimard.

\section{Contribución de autoría}

Este artículo es la transcripción de una conferencia elaborada en su totalidad por Jean-Philippe Bouilloud. La traducción francés-español la realizó el doctor Jorge Walter. 